\title{
Fluoroscopy comes to the rescue in anaesthesia management of a case of ankylosing spondylitis
}

\author{
Chetan M. Pataki
}

Ankylosing spondylosis is always a challenge when patient has severe deformities to choose between general anaesthesia versus regional anaesthesia. Regional anaesthesia is always a choice either at institutionally or at smaller private hospital set ups.

Schewley and colleagues compared regional versus general anaesthesia over 10 years and shown that regional anaesthesia is equally good choice [1].

There are many case reports which suggest that regional anaesthesia could be a safer option in severe Ankylosing spondylosis patients [2].

Author has managed to achieve neuraxial access by using fluoroscopy. However, interpretation of images by fluoroscopy could be difficult for anaesthetists without chronic pain management background. Also, availability of fluoroscopy could be variable as it may be busy in other theatres to be available later for surgery.

Use of ultrasound to view spaces could be useful in cases with difficult neuraxial access to find the space. Most of the anaesthetists practicing regional anaesthesia have expertise in using ultra-sound and also are comfortable to interpret the images. USG could also be helpful in pre-operative setting to identify and plan for central neuraxial blockade [4].

There are many case reports of use of USG guidance for neuraxial anaesthesia in such cases [3].

However, central neuraxial blocks in these patients come with risks. The placement of epidural anaesthesia is technically difficult and is associated with an increased risk of an epidural hematoma.

Wulf reported five out of 51 patients with spinal haematoma occurred in patients with AS in a comprehensive review of spinal haematoma associated with epidural anaesthesia over a 30 -year period. These were related to difficult or traumatic insertion. In his review article, he also mentions Ankylosing spondylosis as one of the risk factors for spinal or epidural haemoatoma [5].

$\mathrm{Li}$ et al also present a case report where patient developed epidural haematoma after epidural anaesthesia for total hip arthroplasty in patient with AS [6].
There is always a chance that epidural anaesthesia might fail or cause inadequate block. Advanced calcified posterior longitudinal ligament can cause a physical barrier to rostral spread of local anaesthesia solution within epidural space [7].

A recent case report described a total spinal anaesthetic following epidural test dose in an AS patient with anticipated difficult airway for a total hip replacement [8].

Peripheral neuraxial blockade is another option and there are plethora of blocks to perform e.g. lumbar plexus block, sacral plexus block, quadrates lumborum block and lower paravetebral block. One needs good skill set and access to ultrasound machine for successful blocks. There are case reports of use of Lumbar plexus block with sacral plexus block and paravertetbral block for hip and knee arhtroplasty [9]. However, such blocks also carry risks of haematoma, failure. Guay et al in Cochrane review concluded that use of peripheral nerve blocks when compared to neuraxial block offer no difference in pain relief, hospital stay, or patient satisfaction [10].

Airway management could be a challenging if general anaesthesia is planned. It could be particularly difficult if there is involvement of temporo-mandibiular joint and cervical spine which can affect the movement. With recent advances in airway adjuncts, general anaesthesia could be a feasible option. Awake fibreoptic intubation is the safest option, especially in those patients where it is not possible to visualise the larynx on indirect laryngoscopy or those with severe chin on chest deformity.

In my opinion, general anaesthesia could be safer option if well planned and executed with help of airway adjuncts like fiberoptic bronchoscope in high-risk Ankylosing spondylosis patients. However, regional anaesthesia with use of USG in difficult cases could also be choice in low-risk patients. One needs to be aware of anatomy if attempting fluoroscopy guided blocks.
${ }^{1}$ Department of Anaesthesia, Musgrove Park Hospital, Taunton TA, United Kingdom.

Address of Correspondence

Dr. Chetan M. Pataki

Musgrove Park Hospital, Taunton TA, United Kingdom.

E-mail:drchetan_pataki@yahoo.co.in

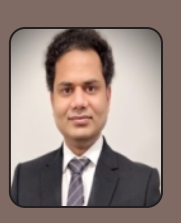

Dr. Chetan M. Pataki

Submitted: March 2021; Reviewed: March 2021; Accepted: April 2021; Published: May 2021

DOI: 10.13107/jaccr.2021.v07i02.180

This is an Open Access article distributed under the terms of the Creative Commons Attribution Non-Commercial-Share Alike 4.0 License (http://creativecommons.org/licenses/by-nc-sa/4.0) which allows others to remix, tweak, and build upon the work non-commercially as long as appropriate credit is given and the new creation are licensed under the identical terms. 


\section{References}

1. Schelew, B.L., Vaghadia, H. Ankylosing spondylitis and neuraxial anaesthesia - A 10-year review. CanJ Anaesth 43,

65 (1996).https://doi.org/10.1007/BF03015960

2. Copuroglu, E. and Sagiroglu, G., 2018. Is regional anesthesia a safe technique for patients with severe ankylosing spondylitis undergoing total hip replacement surgery? International Surgery Journal, 5(8), p.2913.

3. Goyal, R., Singh, S., Shukla, R. and Singhal, A., 2013. Management of a case of ankylosing spondylitis for total hip replacement surgery with the use of ultrasound-assisted central neuraxial blockade. Indian Journal of Anaesthesia, 57(1), p.69.

4. Chin KJ, Chan V. Ultrasonography as a preoperative assessment tool: predicting the feasibility of central neuraxial blockade. Anesth Analg. 2010 Jan 1;110(1):252-3. doi: 10.1213/ANE.0b013e3181bf9e71. Epub 2009 Oct 27. PMID: 19861368.

5. Wulf H. Epidural anaesthesia and spinal haematoma. Can J Anaesth. 1996 Dec;43(12):1260-71. doi: 10.1007/BF03013437.PMID: 8955979.

6. Li J, Qi K, Zhang Y, Xue C, Xu W. Epidural hematoma after total hip arthroplasty in ankylosing spondylitis patient: A case report and review of the literature. Medicine (Baltimore).2017 May;96(19):e6859.

doi: 10.1097/MD.0000000000006859. PMID: 28489779; PMCID: PMC5428613.
7. Hoffman SL, Zaphiratos V, Girard MA, Boucher M, Crochetière C. Failed epidural analgesia in a parturient with advanced ankylosing spondylitis: a novel explanation. Can J Anaesth. 2012 Sep;59(9):871-4. doi: 10.1007/s12630-0129745-1.Epub 2012 Jul 18. PMID: 22806062.

8. Batra, Y. K.1; Sharma, A.1; Rajeev, S.1 Total spinal anaesthesia following epidural test dose in an ankylosing spondylitic patient with anticipated difficult airway undergoing total hip replacement, European Journal of Anaesthesiology: October 2006 - Volume 23 - Issue 10 - p 897-898

doi: $10.1017 / \mathrm{S} 0265021506251378$

9. Mei B, Lu Y, Liu X, Zhang Y, Gu E, Chen S. Ultrasound-guided lumbar selective nerve root block plus $\mathrm{T} 12$ paravertebral and sacral plexus block for hip and knee arthroplasty: Three case reports. Medicine (Baltimore). 2019 May;98(22):e15887. doi: 10.1097/MD.0000000000015887. PMID: 31145347; PMCID: PMC6708964.

10. Guay J, Johnson RL, Kopp S. Nerve blocks or no nerve blocks for pain control after elective hip replacement (arthroplasty) surgery in adults. Cochrane Database Syst Rev.2017 Oct 31;10(10):CD011608.

doi: 10.1002/14651858.CD011608.pub2. PMID: 29087547; PMCID: PMC6485776.

\section{Conflict of Interest: Nil}

Source of Support: None

\section{How to Cite this Article}

Pataki CM | Letter to editor: Fluoroscopy comes to the rescue in anaesthesia management of a case of ankylosing spondylitis | Journal of Anaesthesia and Critical Care Case Reports | May-August 2021; 7(2): 29-30. 